\title{
The Cultural Connotation of Dragon God Belief in the Tao State in Ming and Qing Dynasties*
}

\author{
Yong Sha \\ College of History and Culture \\ Northwest Normal University \\ Lanzhou, China 730070 \\ The Department of History and Culture \\ Gansu Normal University for Nationalities \\ Hezuo, China 747000
}

\begin{abstract}
During the Ming and Qing dynasties, because of Han, Tibetan, Hui nations and other nations in Tao state migrating and aggregating, it constitutes development pattern of the diverse people in the region and religious culture coexisting and interacting. In historical development and social vicissitude, different ethnic groups based on the development demand of symbiotic complementarity and the psychological appeal of interactive integration, have realized the construction of faith on the basis of maintaining certain cultural differences. The dragon belief widespread in Tao state, both reflects the culture of the Han immigrants' recalling to the origin, and the real social scene between Han with and the local Tibetans, Hui nationality cultural exchange and fusion. This kind of superethnic and trans-regional folk sacrificial activities have played down the ethnic consciousness of each ethnic group, while have highlighted the common national identity of all ethnic groups.
\end{abstract}

Keywords-Tao state; ethnic consciousness; religious culture; the dragon faith

\section{INTRODUCTION}

The Tao state in the horizon of time and space is located in the northeast edge of China's inland Qinghai-Tibet plateau and the south of Gan Su province, which is typical of the transition zone between the central plains and the plateau grazing area. The land is "west controlling Dijon, east protecting Huang Long, south next to Fan, north arriving to Shi Ling". It is the gateway of the mainland to the Tibetan areas and the strategic location is very dangerous. It wasn't only regarded by dynasties as "inner protecting Huaxia, but resisting to Yidi", the buffer zone of military garrison strategy, and also the frontier position to control the Tibetan land, pacify the other forces and isolate the Qiang hu. At the same time, the area is a typical national relations' sensitive zone, historically, Qiang, Rong, Tu yuhun, Tubo, Mongolian and other ethnic nomadic migration accumulating and

\footnotetext{
*Fund projects:

1. National Social Science Fund Project in 2015(Project no. : 15BZS060)

2. The Principal Fund Project of Gan Su National Normal University in 2015(Project number: 15-09)

3. Higher Education Research Project in Gan Su province in 2017(Project number: 2017A-138)
}

dispersing freely, and under the influence of different religious culture, ethnic composition in this area is numerous, and ethnic relations are complicated.

\section{The Social SPatial Features of the COEXISTENCE OF MULTI-RELIGIOUS CULTURE IN THE TAO STATE}

Objective conditions such as the natural geographical environment and ethnic distribution of Han, Tibet and Hui in the Tao state, provide a broad perspective for studying the ethnic relations in this region. While the ethnic confrontation, symbiosis and culture in these ethnic relations are different religious belief systems. Tibetan Buddhism, Islam, Han Buddhism, Taoism, folk faith and other religious belief systems have provided a natural sample for the study of the influence of multiple religions on ethnic relations so that a religious ecosystem has been established in the Tao state similar to the natural ecosystem. In the Qing dynasty, on the special field of Tao state, Han, Tibet, and Hui the three main ethnics, under the staggered condition of big area inhabited by several nationalities and little region inhabited by their own, the production and life of the people were bound to be influenced by religion. Chinese Buddhism, Taoism and folk belief, and the heterogeneity of Tibetan Buddhism, Islam, and the religious system, both are relatively independent, and communicate with each other, to form multiple religious belief systems in the region of pluralism and coexistence between normal situation. Its existence is the basic mode of wisdom choice and existence of multi-ethnic religious belief in the temporal transformation sequence.

Tibetan Buddhism has also been able to spread and develop through the nomadic herding, special altitude climate and abundant grassland resources. There is a long history of Zhuo Nichan temple, in which there are 108 temples in its heyday. And the system of political and religious integration, which is the combination of the headmen and the monks, has been used to lead the sacred and secular life of the territory. In addition to some of the agricultural production, the Hui ethnic group is engaged in agricultural production. And some of the Hui ethnic groups near the city of Tao are serving as "middlemen" of 
communication between the Han and the Tibetan people, to start and develop the folk trade. Wherever they went, Islam spread with numerous sects and menhuan, among which the church of the west was one of the local sects. The Han nationality migrated to this place because of settlement, and gradually transplanted and developed religions such as Buddhism, Taoism and folk belief. Among them, the traditional 18th dragon belief in the ancient city of Tao state has a long history and a large scale. Besides, there are also folk beliefs such as Er-lang God and The Golden Flower Empress. Different religious and cultural systems have developed independently in the Tao state, but have formed a spatial relationship of interdependence and mutual influence in the development of history.

\section{A. In the Process of Communication, Different Religious Cultures Have Formed Their Relatively Fixed Geographic Boundaries}

The Tibetan Buddhist temple and believers established a clear support relationship. Therefore, there is a strict subordination relationship between the believers, the belonging temples and patriarch temples, and the village or region of the Buddhist temple is responsible for the support of some larger monasteries. In the spread and the development process of Islam, the religious work was carried out for the center with a mosque, most of the Hui nationality living pattern is "around the temple", forming a relatively scale to live. While the formation of the Han nationality has a lot to do with the migrant settlement in the early Ming dynasty. In the long-term interactions with Tibetan and Hui, they mix nature worship, ancestor worship, primitive witchcraft, Bon religion, Tibetan Buddhism and Chinese Buddhism, Taoism and folk god elements. And after the collision, integration and cultivation of various elements, the belief system of the 18 dragons is gradually formed. The dragon god is supported by the village society, each of the dragon gods has their own feeding scope, called "road". In general, the various religious cultures in the area of Tao state develop independently, forming a relatively fixed communication range, and the less cross-border communication phenomenon.

\section{B. Under Different Religious and Cultural Ecology, Each Ethnic Group Forms a Social Living Space Cooperating with Each Other}

Tao state "belonging to the frontier with cool climate and except hot summer every year, the weather is much cold." the special natural geographical environment made this area the natural dividing line between farming economy and nomad economy, and therefore gave birth to different modes of production and life of local people. The river valley along the Tao river basin is dominated by farming economy, located by villages, mosques, temples of dragon, where Han contact with Hui frequently. Most of the surrounding alpine meadows are dominated by the livestock economy. Tibetan Buddhist monasteries are mainly distributed here. The surrounding Tibetan people live a relatively closed life and have little contact with the outside world. Most of the Han people are engaged in agricultural production, or in handicraft industry, commerce, etc. While the Hui nationality plays the role of "middle man", and carries forward the advantages of the mercantilism, effectively connecting the mainland and Tibetan areas through the circulation of commodities, and realizing the complementarity of economic production methods. The Han, Tibetan and Hui people living in the area of Tao state, despite the history of conflicts, did not form rigid ethnic boundaries and were not excluded from each other because of the uniqueness of culture. Instead, they maintain stable production, consumption and collaborative social living space because of their complementary production and lifestyle.

\section{Tolerance and Respect between Different Religious Cultures}

Tibetan Buddhism is very different from the Islamic culture. "It seems difficult to get along with each other's religious faith, but the people of Hui have learned the Fan language, and good at business. So the friendship is naturally consistent over time." In the thick Tibetan Buddhist culture, other religions are often difficult to intervene. But in the Qing dynasty as Hui people went into the Tibetan area, the Islamic religion was developed, whose iconic building, the mosque, was also built in the Tibetan area, and distributed in the Tibetan Buddhist temple. But the premise is that from the beginning of purchasing the mosque land, you must obtain permission from local people and living Buddha. For example, in the four years of Xian Feng of the Qing dynasty (1854), the Hui merchants Da Wuhaimai asked the mosque Jia Muyang to build in the upper tower. Considering the daily religious activities of Muslims, the temple agreed to build it.

\section{The CONSTRUCTION OF DRAGON BELIEF SYSTEM IN TAO STATE}

It is worth mentioning that in the complex religious belief system of the Tao state, the 18 dragon gods of Tao state are deeply respected by the local Han, Tibetan, Hui, Tu, Mongolian and other ethnic groups. The belief of Dragon Gods in the Tao state is closely related to the large-scale Han immigrant culture during the Ming and Qing dynasties. In the Ming dynasty, a large number of soldiers from the Jiang Huai area were sent to the area of Tao state to garrison with their families following to farm. After long-term communication and integration with local Tibetan and Hui ethnic groups, the folk beliefs of Dragon God in the area were formed. The dragon god is the name of the people in the area of Tao state to the local dragon king and spring god. Some scholars, according to the historical records of Tao state, Tao state hall and other documents, on the basis of the analysis of the local "green seedling" inheritors, the brand order of the dragon god, the name of the gods, the archetype and the location of the temple, etc, believe that the 18 dragon gods are the embodiment of the founding generals or the imperial family. According to Tao, there are dozens of dragon gods, but in the process of spreading, only eighteen gods enjoying the official seal and sacrifice, and attending the May Dragon Festival, especially: Chang Yuchun, Xu Da, Li Wenzhong, Hu Dahai, Guo Ying, Kang Maocai, Ma 
Xiuying, Zhu Liangzu, An Shikui, Zhao Desheng, Zhu Shi, Hua Yun, Guo Ningfei, Wu Dianzhang, Cheng Shijiang, Zhang Desheng, HanCheng, Liu Gui. According to folklore, Tibetan think dragon "five ye" An Shikui maiden in Tibetan and Chang Yuchun has married a Tibetan woman in Kong Do 60 tribal. Therefore the local Tibetan people called him uncle, Li Wenzhong was "the Buddha of Tibetan", and Hui people regarded Chang and $\mathrm{Li}$ as generals in Hui. In addition, Tao state smelt the Tian Chi, known as the master pool in the folk custom, which was regarded as the holy lake by the local people. Every year, the Han people in the surrounding area come to worship the dragon god Chang Yuchun. The Tibetan people will visit the temple at the peak in May holding sacrificial activities. In the same belief system, by means of imagination and legend, the relations between different ethnic groups and mythological characters are constructed, which naturally close the relationship between different ethnic groups.

Although these folk tales can't find the basis of facts, they are widely circulated among local Han, Tibetan and Hui ethnic groups, which has formed the important content of collective memory and local knowledge of ethnic groups, and has evolved into a set of sacred dragon gods cruise sacrificial rites to embody the inclusiveness of different ethnic cultures displayed by cultural symbols and ritual. For example, the temple of Shi Shanlong, the new town of Tao state, is dedicated to Li Wenzhong, the founding commander of the Ming dynasty. He is revered by the Tibetan people as the master of the Buddha, and the title is "the great dragon king of the state of Zhongshi Mountain". The Village of Shi Mountain's dragon god is a typical area of Han and Tibet, and the west and the north are all Tibetan. Stone Mountain dragon temple external shape reflects the typical characteristics of Han and Tibetan culture blend, the appearance of the temple eaves full of mortise structure architectural style of Han nationality, to depict the Tibetan Buddhism dragon kind decorative pattern design, gate design of the roof is in extremely good fortune, as the typical Chinese culture. During the worship of god, Shi Shan temple president wearing of Han style dress and hat, the young men wore Tibetan robes, and eight trumpeters held a long Tibetan trombone for sacrifice music. The lanterns of worship are also Tibetan Buddhist temple objects, which are covered with colored satin sheets or Ha Da. It is visible that whether it is a legend in the myth characters of kinship with people of all nationalities, or specific cultural symbols and sacred ritual performance, make "Sino-Tibetan national produced by blood or emotional associations enhance the identity between the Han and Tibetan ethnic group. Different ethnic groups are explained in different words, so that the same spirit can legitimately appear in their respective deities, which provides convenience for the formation of interracial faith circle. The design of this myth and legend reflects local strategies for enhancing regional belief, and objectively enhances the cultural tension of the private faith itself.

\section{The Cultural Connotation of the Dragon GoD BELIEF IN TAO STATE}

Dragon belief in Tao state, crossing the local Tibetan Buddhism, Islam and other institutionalized religious barriers, on the basis of learning from other kinds of religious elements, after the collision, integration, acculturation, and eventually developed into the local Han, Mongolian, Hui, Tibetan, Tu and other ethnic groups recognized folk belief system. The emergence and development of this unique phenomenon reflects the differences between ethnic groups in the production and living styles and the religious cultural system under the influence of special natural geographical environment in the Tao state. What's more, mutual adjustment and integration of historical phenomenon, also reflects the Han immigrants of the culture of origin remembrance, and the real social scene of the local Tibetans and Hui ethnic cultural exchange and fusion. In this kind of folk belief ceremony performance, different ethnic groups borrow culture symbol mutually, imitate sacrifice ritual, play down the gods' clan identity background, clergy, religious identity, ethnicity and cross-region, gather together in the same field of folk beliefs, share resources of time and space. In the common sacrificial activities, the ethnic groups understand and adjust to each other, not only enhancing the exchange and integration, but also reinforcing the cultural identity of the rural society of Tao state. More importantly, through various nationalities to participate such collective ceremony, from the national identity consciousness into local society knowledge system, be an integral part of the content for the ritual activities now. Although Tao state 18 dragon gods in the folklore come from different ethnics, all of them are the embodiment of the founding fathers for Zhu Yuanzhang in Ming Dynasty, representatives of the national hero, also "patriotic loyal" direct embodiment of core ethics in the traditional Confucian culture. Therefore, this kind of super-ethnic and trans-regional folk sacrificial activities has played down the ethnic consciousness of all ethnic groups, but it has highlighted the common national identity.

\section{CONCLUSION}

Ethnic and religion are inseparable, and religion as the main component of national culture has a very important influence on the values, folk customs and daily life of every nationality. Therefore, in the historical development and social change, with the contraction and stretch of the borders, the change of administrative organizational system, population migration and aggregation, the spread and development of the different religious system, as well as multicultural coexistence and interaction, makes Tao state gradually become a typical area of the academic research relationship between ethnic and religion.

\section{REFERENCES}

[1] (Qing) Zhang Yandu modified, Bao Yongchang etc. Wrote; "Tao State Record", Tai Bei; Publishing written publishing co., LTD, Guang Xu thirty-three years codex photocopy, the 107th -108th page.

[2] Fang Lili; "The Issue of Cultural Ecological Imbalance", Journal of Peking University, the third period of 2001, the 28th page. 
[3] Guo Zhihe; Multiple symbiosis: the mode of religious existence in multi-ethnic scattered areas, Journal of Tibetan ethnic college, the first period of 2014, the 67th page.

[4] (Qing) Zhang Yandu modified, Bao Yongchang etc. Wrote; Tao State Record, Tai Bei; Publishing written publishing co., LTD, Guang $\mathrm{Xu}$ thirty-three years codex photocopy, the 95th page.

[5] Gu Zhegang; The Chinese Nation Is Whole, Northwest Communications, the first period of 1947.

[6] Compilation Committee of Xia River County, Gan Su Province: The Record of Xia River County, Lan Zhou;Gansu Culture Press,1999,the 259th page.

[7] Reference:Wang Shuying, Hao Suming; The Investigation Report On The Status of The Faith of The Dragon God in Tao State - Centered On The Admiration of Chang Yuchun, Northwest National Studies, the fourth period of 2009.

[8] Fang Changfeng; The Ethnic Cooperation of China's Frontier Society -- A Case Study of Qing Miao in the Tibetan Autonomous Prefecture of Gan Nan Tibetan, Proceedings of The 6th Annual Academic Conference of Shanghai Social Science Community, 2008, the 471th page.

[9] Fang Changfeng: The Inter-Ethnic Group And Village Green Seedling Association of Qing Hai-Tibet — - The National Governance Strategy And Local Practice Of Cultural Diversity, Journal Of East China Normal University, the fifth period of 2016,the 62 th page.

[10] Cui Ming: A Preliminary Study On The Multi-Character And Interracial Study of The Folk Religion In the Gan Su National Corridor, Northwest National Studies, the third period of 2015, the 102th page. 